\title{
SIR GORDON HOLMES
}

by

\section{S. BREATHNACH*}

FORTY MILES from Dublin at Castlebellingham on the coast of Co. Louth, Gordon Morgan Holmes was born in Dillon House on 22 February 1876. A scholar at Trinity College Dublin, he graduated B.A. in 1897, being senior moderator and gold medallist, and qualified in medicine the following year. After serving as a resident medical officer in the Richmond Asylum (now St. Brendan's Hospital), he studied briefly in Berlin before devoting two years to neuroanatomical research in the Senckenberg Institute at Frankfurt-am-Main, under the guidance of Carl Weigert (1845-1904) and Ludwig Edinger (1855-1918), before taking a house-physicianship at the National Hospital, Queen Square, London, in 1902, where he became a member of the honorary staff in 1909.

He was consultant to the Royal London Ophthalmic Hospital (Moorfields Eye Hospital) and Charing Cross Hospital, where his diagnostic wisdom helped many patients. Indirectly, too, patients in many lands were to benefit from his skill, for he was above all a teacher, brusque, demanding, tireless, and every aspirant to neurology sought to be his house-physician. Accepting only facts and eschewing speculation, Holmes developed a unique knowledge of the functions of the nervous system in man, especially with regard to cerebral localization and cerebellar symptomatology, and when he published in 1946 his Introduction to clinical neurology ${ }^{1}$ it became the physiological basis for the interpretation and elucidation of neurological disorders. His incisive clarity brought him the editorship of Brain, the most influential neurological journal at the time.

Proceeding M.D. in 1903, Holmes took the M.R.C.P. of London in 1908 and was elected a Fellow six years later. The outstanding event of those early days was the classic he and Henry Head (1861-1940) contributed to Brain in 1911 on "Sensory disturbances from cerebral lesions". ${ }^{2}$ This was the first systematic account of the functions of the thalamus and its relationship to the cerebral cortex. Subsequently Holmes $(1927)^{3}$ pointed out that the freshness of Head's point of view lay in asking not whether a sensation was lost, diminished or spared by a cortical lesion, but what qualities of sensation are localized in the cortex. This task required great refinement of sensory examination and the 1911 paper marked the introduction into clinical neurology of precise methods for mapping the skin.

Holmes was thus well prepared to examine the results of injury to the nervous system suffered by the soldiers in Flanders, where he served in the field. Later he became consulting neurologist to the Ministry of Pensions, and his extensive experience allowed him to interpret the signs of spinal injury (Goulstonian Lecture

*C. S. Breathnach, M.D., Ph.D., Department of Physiology, University College, Dublin. 


\section{Sir Gordon Holmes}

$1915)^{4}$ and the symptoms of cerebellar disease (Croonian Lecture 1922). ${ }^{5}$ His most durable analysis however, will remain the Montgomery Lectures in ophthalmology delivered at Trinity College Dublin in June $1919 .^{\circ}$

In the first lecture on "The cortical localisation of vision" the problem of macular or central vision was clarified, if not finally solved:

... the type of blindness that is produced by superficial injuries of both occipital lobes-that is, by wounds that injure the posterior parts of the striate areas. In all such cases we find peripheral vision intact and central vision abolished. They are consequently evidence that central or macular vision is represented in the most posterior parts of the visual areas, and that this region is not concerned with peripheral sight.

The evidence to be obtained from unilateral lesions confirms this opinion and also supports the conclusion we have already arrived at, that the upper parts of the retinae are connected with the upper parts of the visual cortex and the lower with the lower.?

The hemianopia due to vascular lesions differs from that produced by penetrating gunshot wounds in that the macula is spared. At the posterior end of the striate area the middle and posterior cerebral arteries meet so that the macula gets the benefit of the overlap. The fovea also gets the larger share of cortical retinal representation:

... It is probable, indeed, that the portion of the area striata which frequently spreads over the occipital pole and on to the lateral surface of the brain may be the centre of macular sight. The frequency of paracentral scotomata is consequently accounted for by the more exposed position of this part of the visual area than of that which lies on the mesial surfaces of the hemispheres. It seems very probable, too, that the maculae have anatomically larger representations in the cortex than the less highly specialized peripheral zones of the retinae, and in this we may find the explanation of the frequency of small areas of blindness in the neighbourhood of the fixation point, though the causal lesion may be relatively gross."

The permanence of the scotomata had another lesson for the student of cortical function: "And not only is each segment of the retinae represented in a definite portion of the visual cortex, but this representation is fixed and immutable, so that if a part of the visual cortex be totally destroyed there will be a permanent blindness of the corresponding segment of the visual fields. ... There is no place here for the theory of vicarious representation of the function of parts destroyed by other regions of the brain". 9 Clearly Holmes, was not merely an accurate observer, he came to his task with a prepared mind.

The second lecture was devoted to disturbances of visual space perception. The most obvious symptom was the inability to determine the position in space, in relation to themselves, of objects which the patients saw distinctly and recognized without difficulty. Not only were these patients unable to recognize the spatial relation to themselves of objects they saw, but they could not determine accurately the relative positions of two objects that were simultaneously in view. There was inability to distinguish the absolute and relative lengths and sizes of objects. The inability to localize objects in space by vision alone was very obvious when the patients were allowed to walk about; repeated collisions and disorientation even in familiar surroundings were matched by loss of topographical memory of old haunts.Stereoscopic vision, or the power of recognizing thickness and depth in solid objects, was severely affected in only one of the eight patients concerned. No patient could count correctly 


\section{C: S. Breathnach}

beyond four or five similar objects placed before him, but could count quite readily when allowed to touch the objects with the hands. With regard to the position of the anatomical lesions Holmes wrote: "In all my eight cases the condition described above was associated with gunshot wounds of the head which involved the posterior and upper parts of both parietal lobes. Post-mortem examinations were obtained in two cases; in both the lateral surfaces were injured in the neighbourhood of the angular and supra-marginal gyri, while the missiles passed through the mesial surfaces immediately dorsal or posterior to the splenium of the corpus callosum."10

Although not a definitive study comparable to the opening lecture, this was a valuable contribution on the visual defects resulting from damage to the parietal lobe. The diversity of clinical consequences resulting from interference with the parietal assimilation of visual and somatic sensory components necessary for the perception of form is reflected in the detailed histories of these patients which Holmes had published a year earlier. ${ }^{11}$

War casualties also gave Holmes a further opportunity to examine the symptoms of acute cerebellar injury, ${ }^{12}$ for since his resident days the cerebellum had claimed his attention. Probably the most notable distinction of his report in 1917 is that drawn between phasic and tonic myotatic reflexes: "The state of the tendon jerks has been generally taken by clinicians as a measure of tone, and yet it is the rule that even in the toneless limb of a cerebellar patient the knee-jerk and similar reflexes are not abolished, and the excursion of the jerks may be even larger than on the normal side. . . . The presence of the knee-jerk is consequently not an argument against the existence of atonia in cerebellar disease."18

Nowhere is the influence of Sherrington's The integrative action of the nervous system more verifiably apparent in neurophysiology than in the development of Holmes's understanding of the cerebellum. One of his earliest challenges when he returned from Edinger's laboratory to clinical medicine in London came from cerebellar symptomatology ${ }^{14}$ and, in the year after its publication, Holmes published a painstaking account ${ }^{15}$ of a form of familial degeneration of the cerebellum, appending a detailed review ${ }^{16}$ in which he attempted to classify cerebellar disease.

In the report of the family history ${ }^{17}$ one can trace the influence of the phrenologist, F. J. Gall, and his localization of the reproductive instinct, or amative principle, in the cerebellum. ${ }^{18}$ Holmes remarked on the association between cerebellar degeneration and gonadal underdevelopment with altered libido, alteration not necessarily linked though indicative to him of a hereditary tendency to degenerative change. The link, in fact, may have been uncovered in the discovery that the cerebellum is just as sensitive to progesterone as is the median eminence or the amygdala. ${ }^{10}$ To be sure, Sherrington's epitome "the head-ganglion of the proprio-ceptive system" 20 is mentioned, though not quoted by reference, but the paper ${ }^{21}$ remains a detailed anatomical and histological study, and the added review ${ }^{22}$ is strictly what its title declares: a classification based on morbid anatomy and pathogenesis. Even in the fertile mind of Holmes the Sherringtonian seed needed time to mature.

A decade later, maturation is plainly evident in succeeding issues of Brain. In one number alone the principles of integration are used to examine and understand the sequelae of gunshot injuries in World War I as exemplified in the automatic bladder, ${ }^{23}$ 


\title{
Sir Gordon Holmes
}

in spinal $\operatorname{man}^{24}$ and in cerebellar injuries. ${ }^{25}$ Subsequently, in the Croonian Lectures (1922), ${ }^{26}$ in a discussion following a series of papers on the cerebellum (1927) ${ }^{27}$ and in the Hughlings Jackson lecture (1939), ${ }^{28}$ Holmes returned to the subject, sifting the observations he and others had made in the meantime but not altering in essence the theme of 1917. ${ }^{29}$ Babinski's adiadochokinesis; Bárány's past-pointing, and the rebound phenomenon, described originally by Holmes and Stewart in $1904,{ }^{30}$ are discussed in detail. The pitfall of exclusion of localization by negative evidence is avoided, but one paragraph, so like Sherrington in style and strategy, illustrates how wisdom transmutes a wealth of information:

\begin{abstract}
We must consequently conclude that in addition to its influence on tone, and that by which it assures the regularity and maintenance of muscular contractions and the immediate and effective response of subcortical mechanisms to cerebral impulses, the cerebellum also exerts a regulating and co-ordinating influence on the motor centres that effect voluntary movements and by this means assures their harmony, precision and correct range. This does not mean that the cerebellum puts into play the muscles necessary for the accomplishment of complicated movements. It is an organ which has evolved on the afferent rather than on the motor side of the central nervous system. But it receives and integrates proprioceptive impulses from all parts of the body, and by virtue of these it keeps the motor mechanisms in such a state of "tone" that they can react promptly and efficiently to voluntary impulses, and it thus assures the correct co-operation of the separate motor centres that are concerned in individual acts. ${ }^{21}$
\end{abstract}

Although Holmes, among others, added to our information by his perceptive observations it is as true today as it was in 1906 that "knowledge is not ripe as yet for an adequate definition of the function of the cerebellum". ${ }^{32}$ That the effects of injury to an organ developed from the alar plates of the neural tube, destined as they are to provide predominantly sensory neurones, should fall almost exclusively on the motor system is a paradox certain to engage a mind nurtured on The integrative action.

In the Croonian Lectures on the cerebellum before the Royal College of Physicians in 1922, Holmes remarked: "The value to physiology of conclusions obtained from a careful analysis of functional abnormalities in man is obvious in the case of the central nervous system, as the complex evolution of the human brain distinguishes it in many respects from that of the animals usually employed in experimental research, and more particularly since the intelligent co-operation of our subjects enables us to investigate the anomalies produced by nervous lesions more intimately and more thoroughly than is often possible in animals." 33

These papers explain Holmes' stature as a neurologist, but also reveal his skill as an analyst of function. The opening Montgomery Lecture is a cornerstone to our understanding of cerebral localization but is also a milestone in the physiology of vision. In this Holmes was as much physiologist as neurologist, a duality which should occasion no surprise when his training, so like his friend Head's in "basic science" is recalled. Under Ludwig Edinger's guidance he had been initiated into the intricacies of functional neurohistology. In 1933 Holmes was elected a Fellow of the Royal Society.

In 1892 Franz Nissl (1860-1919) showed that removal of the facial nerve in rabbits was followed by swelling of the neurones in the facial nucleus on that side in the floor of the fourth ventricle and by disappearance of their chromophilic granules. ${ }^{34} \mathrm{He}$ was the first to show that the latter are specifically stained by basic dyes ${ }^{36}$ (methylene 


\section{S. Breathnach}

blue, toluidine blue, pyronin), and the changes in the cell whose axon is injured have come to be known as Nissl degeneration, the central nervous system counterpart of Wallerian degeneration. In 1895 Gustav Mann (1864-1921), like A. V. Waller (18161870) a physiological histologist, using toluidine blue, ${ }^{36}$ showed that Nissl granules disappear from anterior horn cells in the spinal cord of dogs after extreme muscular exercise; the vulnerability of such exhausted cells to polio virus explains the extent and severity of poliomyelitic paralysis of muscles subjected to excessive activity at the time of infection, and are markedly depleted in the cytoplasm of pyramidal cells in the occipital cortex after exposure of the eye to light. He concluded that during rest "chromatic materials are stored up in the nerve cell, and these materials are used up by it during function". ${ }^{37}$ Holmes (1903) found that Nissl substance disappears from the anterior horn cells of frogs during strychnine convulsions; when convulsions are prevented by cooling the frogs in ice the loss of Nissl granules was arrested in spite of full doses of strychnine. The loss of Nissl substance was, therefore, the direct result of neuronal "overwork" and was not caused by any toxic action of the drug. ${ }^{38}$

Holmes proposed to continue his morphological studies but the necessary subsidy was diverted from Edinger to Ehrlich for the development of salvarsan. The functions Holmes wished to study most were those of the highly differentiated nervous system of man. He had, after all, set out on his peregrinations with the aid of the Travelling Prize in Medicine of his University and the Stewart Scholarship in Nervous and Mental Diseases awarded to him in $1899 .{ }^{39}$

Even in the crowded clinical years he found time for fresh neuroanatomical studies and one paper is of renewed interest today. The fact that the brain stem reticular formation can be widely influenced by sensory stimulation led to the supposition that collaterals entered it from the sensory pathways, particularly the lemniscal system. It is now known that such collaterals are few in number and that the influence is directly mediated, especially through spino-reticular components of the spinothalamic tract, originally adumbrated by Batten and Holmes in 1913 when they discovered that "ventrolateral fibres diminish rapidly in numbers" when they reach the level of the olives. ${ }^{40}$ And just as indelible as his training by Edinger at the Senckenberg Institute, so too his boyhood on a farm made him an avid gardener when he retired to Farnham in Surrey, where he died on 29 December 1965.

To Wilder Penfield, who studied under Ramon y Cajal and Sherrington, among others, Holmes was "one of the finest teachers" he had known; "beneath the exterior of a martinet there was an Irish heart of gold"."11 Graduate students came from many lands to his ward rounds. For those less fortunate the orderly examination of the nervous system which developed from his infinite capacity for precision is described in the Introduction. It is an unpretentious little book, ripe with the experience of the years and the wisdom of Sir Thomas Browne's preface to the Pseudoxia Epidemica "For Knowledge is made by oblivion, and to purchase a clear and warrantable body of Truth, we must forget and part with much we know."42

\section{REFERENCES}

1. G. Holmes, Introduction to clinical neurology, Edinburgh, Livingstone, 1946.

2. H. Head and G. Holmes, 'Sensory disturbances from cerebral lesions', Brain, 1911, 34: 102-254. 


\section{Sir Gordon Holmes}

3. G. Holmes, 'Disorders of sensation produced by cortical lesions', ibid., 1927, 50: 413-427, see p. 413.

4. G. Holmes, 'On the spinal injuries of warfare', Br. med. J., 1915, ii: 769-774, 815-821, 855-861.

5. G. Holmes, 'Clinical symptoms of cerebellar disease and their interpretations', Lancet, 1922, i: 1177-1182, 1231-1237; ii: 59-65, 111-115.

6. G. Holmes, 'The Montgomery Lecture in Ophthalmology. I. The cortical localisation of vision', Br. med. J., 1919, ii: 193-199. 'II. Disturbances of visual space perception', ibid., 230-233.

7. Ibid., p. 194.

8. Ibid., p. 196.

9. Ibid., p. 197.

10. Ibid., p. 232.

11. G. Holmes, 'Disturbances of vision by cerebral lesions', Brain, 1918, 40: 461-535. It is noteworthy that only one of Holmes's eight patients suffered from aphasia although the lesions were in or close to the supramarginal gyrus and part of the superior parietal lobule which Head associated with his curious "semantic aphasia" (H. Head, 'Speech and cerebral localisation', ibid., 1923, 46: 355-528).

12. G. Holmes, 'The symptoms of acute cerebellar injuries due to gunshot wounds', ibid., 1917, 40: 461-535.

13. Ibid., p. 519.

14. T. G. Stewart and G. Holmes, 'Symptomatology of cerebellar tumours-a study of forty cases', ibid., 1904, 27: 522-591.

15. G. Holmes, 'A form of familial degeneration of the cerebellum', ibid., 1907, 30: 466-489.

16. G. Holmes, 'Review - an attempt to classify cerebellar disease with a note on Marie's hereditary cerebellar ataxia', ibid., 1907, 30: 545-567.

17. Op. cit., note 15 above.

18. G. Combe, A system of phrenology, 2nd ed., Edinburgh, Anderson, 1825, pp. 61-65. Under the heading "Amativeness", Combe writes on p. 61. "The cerebellum is the organ of this propensity .... . The size is indicated during life by the thickness of the neck in these parts." Gall's discovery of this organ is described on pp. 62-63 and confirmation by Spurzheim and others on p. 63. The experiments of Flourens and Magendie are discussed but refuted: " . . . the fact is, that all parts of the nervous system are so intimately connected, that the infliction of injuries is not the way to determine the functions of any, even its least important parts."

19. F. Piva, P. S. Kalra and L. Martini, 'Participation of the amygdala and of the cerebellum in the feedback effects of progesterone', Neuroendocrinology, 1973, 11: 229-239.

20. C. S. Sherrington, The integrative action of the nervous system, New Haven, Conn., Yale University Press, 1906, p. 348.

21. Op. cit., note 15 above.

22. Op. cit., note 16 above.

23. H. Head and G. Riddoch, 'The automatic bladder, excessive sweating, and some other reflex conditions in gross injuries of the spinal cord', Brain, 1917, 40: 188-263.

24. G. Riddoch, 'The reflex functions of the completely divided spinal cord in man, compared with those associated with less severe loss', ibid., 1917, 40: 264-402.

25. Op. cit., note 12 above.

26. Op. cit., note 5 above.

27. G. Holmes, 'A symposium on the cerebellum' [discussion], Brain, 1927, 50: 385-388.

28. G. Holmes, 'The cerebellum of man', ibid., 1939, 62: 1-30.

29. Op. cit., note 12 above.

30. Op. cit., note 14 above.

31. Op. cit., note 12 above, p. 528.

32. Op. cit., note 19 above, p. 348.

33. Op. cit., note 5 above, p. 1177 . 


\section{S. Breathnach}

34. F. Nissl, 'Ueber die Veranderung der Ganglion am Facialskern des Kannichens nach Ausreissung der Nerven', Allg. Z. Psychiatr., 1892, 48: 197-198.

35. Ibid., p. 197.

36. G. Mann., 'Histological changes induced in sympathetic, motor and sensory nerve cells by functional activity', J. Anat. Physiol., 1895, 29: 100-108.

37. Ibid., p. 108.

38. G. Holmes, 'On morphological changes in ganglion cells', Z: Allg. Physiol., 1903, 2: 502-515.

39. Obituary notices: Br. med. J., 1966, i: 111, 177; Lancet, 1966, i: 101.

40. F. E. Batten and G. Holmes, 'The endogenous fibres of the human spinal cord', Brain, 1913, 35: 259-275.

41. W. Penfield, 'Lights in the great darkness', J. Neurosurg., 1971, 35: 377-383.

42. Geoffrey Keynes (ed.), The works of Sir Thomas Browne, London, Faber \& Gwyer, 1928, vol. 2, p. 3. 